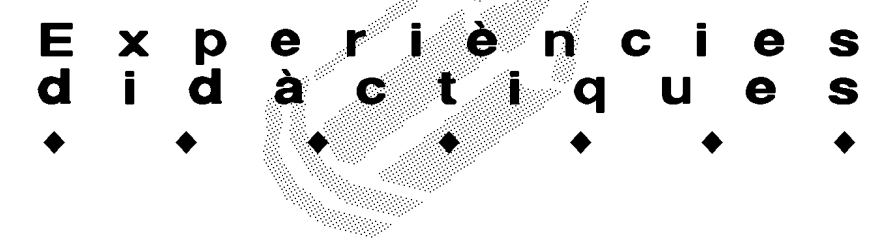

\title{
UN TRACTAMENT VIU DEL MEDI AMBIENT
}

\author{
Anna Ferrando Agustí i Pere Bosque Ripollés. Mestres del CEIP “Antoni Roig”. Torredembarra.
}

EI CEIP "Antoni Roig" de Torredembarra és una escola centenària, fundada l'any 1892 per qui li ha donat nom. Actualment, com moltes escoles del litoral català, està saturada d'alumnes: tenim tots els cursos triplicats excepte dos, amb una ratio de 24 alumnes per classe. Donat que a la vila s'ha posat en funcionament una altra escola $\mathrm{i}$ ja som tres els col-legis de Primària, en un futur esperem baixar les ratios i passar a tenir els cursos duplicats, que és per al que estan preparades les nostres instal-lacions.

Al CEIP busquem un tipus d'educació que, a partir de la realitat que ens envolta, faci una anàlisi, un estudi i una valoració d'allò que estudiem. Entenem que els coneixements teòrics han de trobar l'aplicació pràctica per tal de motivar els alumnes. Busquem un ensenyament actiu i adaptat a les seves necessitats.

Un eix bàsic és el de transmetre valors com els del respecte a la natura, defensar el medi mitjançant la protecció i el pertinent coneixement o la conservació sostenible. D'aquesta manera creiem que ajudem a crear les condicions necessàries per a la convivència, el diàleg i el respecte entre els pobles. I si els nostres alumnes creixen amb valors com aquests és previsible un món millor per al dia de demà. L'aprenentatge en i des de la natura és una oportunitat excel-lent per a plantejar i portar a terme els objectius d'una educació integral, i al mateix temps suposa un procés d'aprenentatge on es combinen activitats d'observació, investigació, comparació, experimentació, consulta, etc.

Conseqüents amb aquest planteig, cada dia realitzem activitats que d'alguna manera afecten el medi ambient i que incideixen en la vida que ens envolta i en la nostra forma de viure. Moltes d'aquestes accions, amb una mica de bona voluntat i amb uns mínims coneixements, poden fer que aquest medi ambient, tan maltractat darrerament, recuperi una part del seu bon estat. I uns per un costat i els altres per l'altre, uns aportant una mica i els altres molt, a poc a poc hem de fer que el nostre entorn sigui més agradable. Si, a més a més, som nosaltres els que canviem, des de les escoles, des de les cases, des dels pobles i tirem endavant projectes d'aquest tipus, potser aconseguirem que, aquells que més contaminen, decideixin d'una vegada escoltar els milers i milers de persones que volem un món millor. En això estem.
D'aquesta forma s'ha d'entendre que actes com netejar el pati a les escoles, reciclar els papers i els residus que es produeixen a la llar, no utilitzar tovallons d'un sol ús al menjador escolar, implicar-se a esmorzar de manera saludable, etc. no són actes que no tinguin cap valor, ans al contrari. De fet, si un de petit ho aprèn, ho recordarà per sempre, i si també ho ensenya als altres, millor que millor.

Al CEIP tenim molt clar que hem de començar a l'escola a inculcar als nostres alumnes l'estima per la natura. Per això des del 1r curs d'educació infantil fins al 6 è de Primària, realitzem tota una sèrie d'activitats encaminades a aconseguir aquest objectiu. Activitats realitzades a l'escola, al seu entorn més proper, a la platja, especialment als aiguamolls que tenim la sort de conservar, amb sortides d'un dia a llocs relativament propers o de colònies per les diferents zones de Catalunya, aprofitant el potencial del nostre país, també serveixen perquè els nostres alumnes es conscienciïn dels problemes que hi ha actualment al món. I si a tot això hi afegim el suport de les regidories d'Ensenyament i de Medi Ambient de l'Ajuntament, de l'Associació de Mares i Pares de l'escola i la col-laboració dels mateixos pares dels nostres alumnes, doncs tenim totes les possibilitats per poder portar a terme el que ens proposem.

\section{Què fem?}

Les activitats que realitzem, les podem dividir en dues parts: les que tenen un ajut de l'Ajuntament i les que realitza l'escola pel seu compte. Com que aquesta aportació vol ser un mirall o una modesta font d'idees perquè altres centres puguin realitzar activitats relacionades amb el medi ambient i la natura, passem a exposar totes les activitats que fem a l'escola diferenciant-les, precisament, pel tipus d'organització.

Les activitats que ens subvenciona l'Ajuntament són:

$L$ 'hort escolar. En un lateral del pati i amb una petita tanca de protecció, tenim un espai de conreu. Uns monitors contractats per l'Ajuntament vénen una vegada a la setmana $\mathrm{i}$, amb els alumnes de $2 \mathrm{n}$ de Primària, realitzen activitats com l'observació i experimentació directa de l'hort i quins són els diferents tipus de cultius, apropant-se d'aquesta manera de forma senzilla i activa a la terra. Els alumnes participen en totes les activitats: han de preparar la terra utilitzant les eines adequades, 


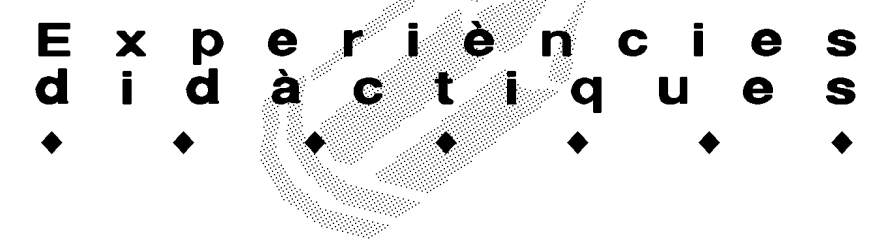

han de posar els noms de les plantes sembrades, han de regar-les... i finalment han de collir els fruits que els ha donat la terra per portar-los a casa i menjar-se'ls.

Aprendre a observar i respectar la natura. Des del curs 1994/95 portem a terme unes activitats amb aquest títol genèric. Generalment els tècnics que es contracten pertanyen a una empresa de Reus i les activitats que porten a terme, les escollim entre les que ells ens presenten. Aprofitem els aiguamolls dels Salats i Muntanyans que tenim a prop, i a partir d'aquí es preparen una sèrie d'activitats per a tots els cursos de Primària. Prèviament a la sortida preparem xerrades sobre el tema a treballar, segons l'edat dels alumnes, i posteriorment es fa el treball de camp. Com que els aiguamolls estan una mica apartats, cal contractar autobusos i, tenint en compte el gran nombre d'alumnes per curs, preparar una sortida d'aquest tipus és prou laboriós per als monitors i mestres perquè la ratio sigui l'adequada.

Les activitats van des de recollir tresors a la platja, parlar sobre les marees, observar els efectes del mar com a agent geològic, etc. Als aiguamolls s'observa la fauna i la flora d'aquella zona. Cal dir que aquesta activitat és una de les més interessants que es realitzen, gràcies a la varietat de vegetació i fauna que poden observar els alumnes. Els prismàtics, els quaderns de treball $\mathrm{i}$ uns senzills dibuixos per identificar plantes $\mathrm{i}$ animals són indispensables per poder treballar en aquest paratge.

Altres activitats que realitzem són:

Viu la natura $(X X X X)$. És una sortida a l'entorn més proper a l'escola (un petit bosc a $500 \mathrm{~m}$ ) on es fa un estudi sobre els canvis que experimenten les plantes al llarg de l'any o les adaptacions dels organismes vius a les condicions del medi.

Els nostres arbres (a 1r). Basada a conèixer l'entorn més proper, com són els arbres que tenim al pati: el nom, les característiques, les qualitats, i sobretot les necessitats i atencions que requereixen per créixer envoltats d'infants.

Taller del paper reciclat (2n). Aprenem el procés de fabricació d'aquest paper, de manera que cada nena i nen es fabrica el seu propi paper.

$L$ 'ecocompra $(X X X)$. Es realitza una compra responsable i respectuosa amb l'entorn que afavoreixi la reutilització, el reciclatge i la reducció de residus.

Plantes aromàtiques i medicinals (4t). Descobrir algunes plantes medicinals, les seves propietats i aplicacions sempre és interessant,i així poder comprovar que també podem conèixer els "remeis de la iaia".

Joc d'orientació (5è). Al pati de l'escola, i després en l'entorn més proper, els alumnes aprenen a orientarse a la natura: han de trobar un tresor amagat ajudant- se d'una brúixola.

Elaboració de fòssils (6è). Creació de motlles semblants a com ho fa el procés natural de fossilització.

Totes aquestes activitats són una mostra de les possibilitats que oferim. Cada activitat és valorada i cada any és diferent per al curs que la porta a terme.

Altrament hi ha diverses activitats organitzades per l'escola de forma incardinada en el currículum. Són aquestes:

El temps. Cada matí dos alumnes de 6è prenen les dades meteorològiques d'una caseta que tenim al pati: temperatura màxima, mínima i actual, pressió, vent, pluja... i després són anotades en un tauler que hi ha a l'entrada de l'escola perquè estigui a disposició de tothom. Aquesta activitat és molt valorada per tots els cursos, pels monitors del l'hort escolar i per persones de fora de l'escola que vénen a consultar les dades recollides. Adquirir els hàbits i destreses d'observació directa i indirecta de fenòmens, la utilització dels aparells de la caseta meteorològica i la presa i recopilació de dades, és el principal objectiu d'aquesta activitat.

El paper reciclat. A totes les classes i dependències de l'escola hi ha dues papereres: en una es llencen tots els papers i a l'altra els altres residus. Cada dijous els alumnes de 6è passen per tota l'escola a recollir el paper, el pesen i el porten als contenidors que hi ha més a prop de l'escola, on es diposita. Els biòlegs de l'Ajuntament ens han indicat que per cada $50 \mathrm{~kg}$ de paper recollit salvem un arbre. El resultat el podeu veure al gràfic 1.

Recollida dels papers del pati. Aquesta activitat la duen a terme cada dia els alumnes de $1 r$ a 5 è. La pretensió és aconseguir que totes les nenes i nens es conscienciïn que el terra del pati, dels carrers, dels boscos i de tot arreu, cal que el conservem net.

\begin{tabular}{|c|c|c|c|c|}
\hline & $\begin{array}{c}\text { Curs } \\
1999 / 00\end{array}$ & $\begin{array}{c}\text { Curs } \\
2000 / 01\end{array}$ & $\begin{array}{c}\text { Curs } \\
2001 / 02\end{array}$ & $\begin{array}{c}\text { Curs } \\
2002 / 03\end{array}$ \\
\hline $\begin{array}{c}1 \mathrm{r} \\
\text { trimestre }\end{array}$ & 雨 & 雷需 & 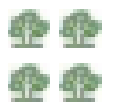 & 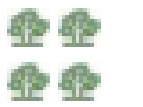 \\
\hline $\begin{array}{c}2 \mathrm{n} \\
\text { trimestre }\end{array}$ & 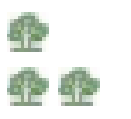 & 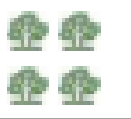 & $\begin{array}{l}\text { 雨需 } \\
\text { 雨然 }\end{array}$ & 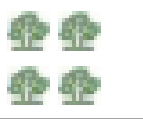 \\
\hline $\begin{array}{c}3 r \\
\text { trimestre }\end{array}$ & 雨 & 雨 & 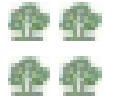 & 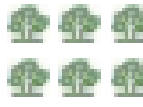 \\
\hline
\end{tabular}

Gràfic 1. Àrbres salvats amb la recollida de paper a l'escola ( 1 àrbre $\approx 50 \mathrm{~kg}$ de paper) 


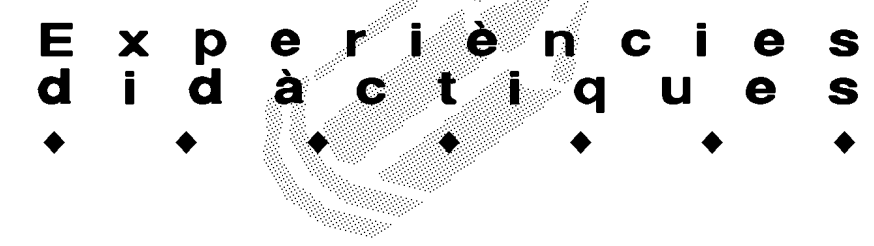

Esmorzars saludables. El Departament d'Ensenyament, conjuntament amb el Col.legi Oficial de Farmacèutics, ha organitzat la campanya "esmorzars saludables" per tal d'intervenir en els hàbits alimentaris de la població escolar promovent els aliments propis de la nostra terra: oli, avellanes... i deixant de banda les influències dels productes que ens ofereixen constantment els mitjans de comunicació. Amb aquesta acció volem incidir en el procés de formació i de responsabilització de l'alumne, amb la finalitat que adquireixi els

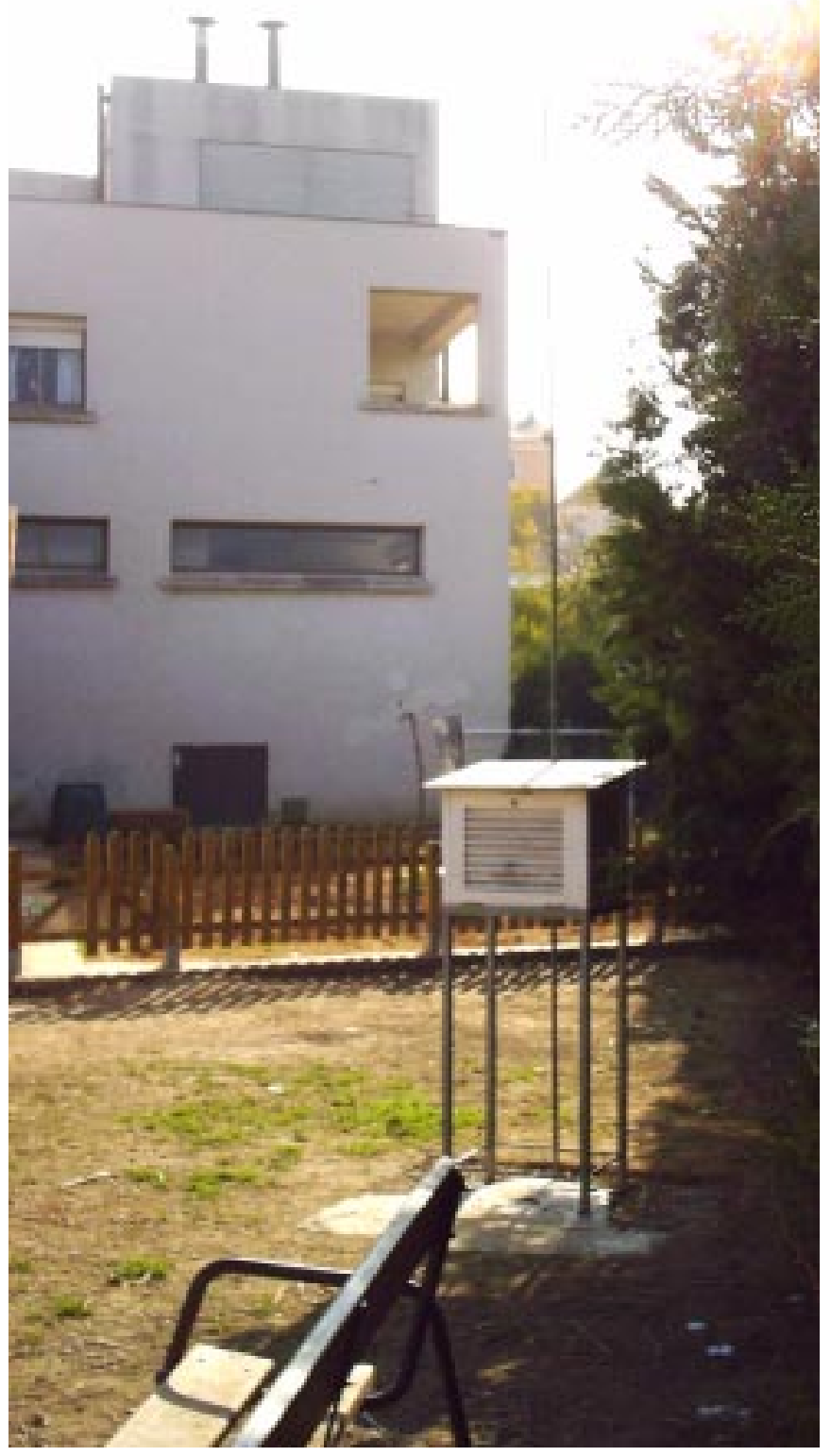

Caseta meteorològica coneixements, les actituds $\mathrm{i}$ els hàbits bàsics per a la defensa i la promoció de la salut individual i col-lectiva.

Intentarem sensibilitzar els nens i preparar-los perquè a poc a poc adoptin un estil de vida com més sa millor $\mathrm{i}$ unes conductes positives de salut.

Sortides escolars. A la tardor els alumnes de P4 i P5 fan una sortida a Vilanova de Prades. Una sortida que ensenya als alumnes d'on surten les castanyes, amb la finalitat afegida que comencin a potenciar el respecte envers el medi ambient.

Els alumnes de $3 r$ fan una visita al mas Baget d'Alforja, on realitzen el taller dels animals de granja. Aquí pretenem que les nenes i nens reconeguin els animals de la granja, la seva alimentació, els productes derivats, etc. Els alumnes d'Educació Infantil de P3 fan una sortida semblant a una granja del Catllar.

Els alumnes de 6è van un dia al delta de l'Ebre. Allí visiten l'ecomuseu, les basses de l'Encanyissada o la Tancada per veure especialment la fauna, la desembocadura del riu i el conreu de l'arròs, els camps i la cooperativa arrossera. Aquesta sortida està pensada com un primer contacte per part dels alumnes amb els ambients naturals del delta.

Sortida al garden de la vila. Els més petits de l'escola visiten les instal-lacions i són obsequiats amb una petita planta: hauran de tenir-ne cura fins a final de curs.

Colònies escolars. Els alumnes de $2 \mathrm{n}$, $4 \mathrm{t}$ i Gè van tres dies de colònies a diferents indrets de Catalunya. Amb aquestes estades també procurem que estiguin en contacte amb la natura i l'aprenguin a respectar. Les nenes i nens de $2 n$ curs van a l'alberg de la Generalitat a l'Espluga de Francolí o a Coma-ruga, i segons un lloc o altre, estudien el món rural o el món marí. Els de 4t van cada any a la granja-escola de Juneda (les Garrigues) on passen tres dies amb els animals de granja i I'hort, aprenen a transformar els aliments, veuen el procés de la mel i decobreixen el món rural.

Les nenes i nens de 6è van a Olot per visitar llocs com els volcans d'aquella zona i la fageda d'en Jordà. Alguns anys van a l'Escala, i no cal dir que allí la visita més important és la que fan durant tot un dia als aiguamolls de l'Empordà.

En resum, creiem que la investigació $i$ el treball directe del medi constitueix un immillorable aprenentatge que no hem de deixar passar per lligar l'escola al seu entorn. Això és el que pretenem $\mathrm{i}$ amb aquestes activitats $i$ altres que portem a terme a l'escola, creiem que ho estem aconseguint. Mestres, mares, pares i entitats fan que això sigui possible. 